\title{
The Impact of ScienceWare and Foundations on Students' Attitudes Towards Science and Science Classes
}

\author{
Steven J. Stratford ${ }^{1,2}$ and Elizabeth A. Finkel ${ }^{1}$
}

\begin{abstract}
In this paper, we describe changes in students' ideas about science classes, attitudes about science, and motivations for studying science, in a classroom designed to support projectbased science learning. Using a survey designed to provide a measure of students' attitudes towards science classes and science, we have compared students enrolled in a traditional high school biology course, with students enrolled in an integrated, project-based science course called Foundations I. Survey responses were analyzed to look at differences between and within two groups of students over the course of one school year. In general, the results of this study suggest that providing students with opportunities to collect and analyze their own data in science classes results in a change in students' ideas about science classrooms. Foundations I students' increased tendency to agree with statements about 'using information,' 'drawing conclusions,' and 'thinking about problems,' implies a change in their understanding of what it means to do science in school. These students, in contrast to students in the traditional Biology course, no longer describe their science experience as one of memorization, textbook reading, and test taking. Instead they see science class as a place in which they can collect data, draw conclusions, and formulate and solve problems.
\end{abstract}

KEY WORDS: Attitudes; science education; project-based science; technology.

\section{INTRODUCTION}

Recently, many science educators have advocated a project-based approach to learning science in which students are given opportunities to actively construct scientific knowledge through engaging in solving real, meaningful, science problems (Krajcik et al., 1994; Roupp et al., 1992; Blumenfeld et al., 1994). Such classrooms are seen as places in which students can engage in higher order thinking skills such as data analysis, problem formulation, and synthesis. In addition, project-based science involves students and teachers in the use of cognitive tools such as computers, telecommunications software, and microcomputer-based labora-

\footnotetext{
${ }^{1}$ The University of Michigan, School of Education, Department of Educational Studies, Ann Arbor, Michigan 48109-1259.

${ }^{2}$ Correspondence should be directed to: Steven J. Stratford, 1465 Chandler, Lincoln Park, Michigan 48146. (e-mail: sstrat@umich.edu)
}

tories in order to transform classrooms into environments in which knowledge construction can take place. Technological tools also help students represent their understanding easily, and in a number of different ways (Krajcik et al., 1994).

In the classroom we will describe here, students have been provided with numerous technological tools, including Macintosh Powerbook computers; hardware and software to support data collection, data analysis, modeling, and presentation; and access to telecommunications hardware and software. These tools have been designed to support a range of project-based practices, and an innovative curriculum is being developed and implemented in which students use these tools while collaborating to carry out a series of long term, authentic scientific investigations.

Much of the previous research conducted in such classrooms has focused on the ways that teachers change their practices in order to create environments in which students can learn through working collabo- 
ratively to solve authentic problems (e.g. Krajcik et al., 1994; Marx et al., 1994). In this study, however, we are concerned with changes in students' ideas about science classes, their attitudes about science, and their motivations for studying science within a technologyrich investigatory environment. In order to better understand these changes, we have compared changes in attitudes of students enrolled in a traditional high school biology course in which students had very little access to technology, with those of students enrolled in an integrated, project-based science course enriched with technological learning tools.

\section{TECHNOLOGY AND PROJECT-BASED SCIENCE}

Project-based science has five hallmarks: investigations focused around a driving question; studentdeveloped inquiries; student-produced artifacts which reflect their understanding and knowledge; student, teacher, and community collaboration to find answers to the driving question; and the use of cognitive tools-computers, associated software, and data-gathering technologies to assist students in active knowledge construction. The content of the project-based curriculum is embedded within the context of the driving question and within the scope of the investigations. Students utilize the data they collect and analyze, the resources they draw upon for additional information, and the discussions they have with peers, teachers, and mentors, to construct scientific knowledge within an atmosphere of inquiry.

Technology plays a central role in the projectbased science classroom. Students use microcomputer-based laboratories to collect and analyze data. They collaborate in their investigations and then report their findings to their peers and often to the public by producing multimedia presentations involving graphics, digitized video, and sound. This often means that students must draw upon knowledge and skills from disciplines that are isolated from each other within the typical high school curriculum, such as math and language arts. Through the emerging technologies of telecommunication, students access sources of information that were previously unavailable to them, such as government databases and Internet information services. They contact experts in the field via electronic mail for information or advice. They also use electronic mail to communicate asynchronously with their teachers and with each other, which enhances their collaboration efforts.
The Foundations I classroom makes use of all of the above-mentioned technologies. Students are given portable computers to use in all aspects of their investigations from data gathering and analyzing to reporting. Equipment for digitizing video and sound is provided, including equipment such as a video microscope with which students can record and digitize macro- and micro-scopic objects, a video snapshot camera with which they can record and digitize pictures such as laboratory procedures, settings of their investigations, or group activities, and video to digital movie conversion equipment. In addition, students are provided with the software tools necessary to support all of these activities, including integrated software for word processing, spreadsheet, database, and graphics presentations; 3-D video modeling; and digital still photograph, audio, and movie production software. Students require a great deal of support to be able to use technological tools such as these productively; the HI-C research group at the University of Michigan, headed by Elliot Soloway, provides technological support as necessary before, during, and after class.

Using computers in biology classes for laboratory, demonstration, and classroom activity has been shown to improve attitudes of students enrolled in those classes (Hounshell and Hill, 1989). It has been our observation that students in the Foundations I classroom seem to be deeply involved in the course, not only cognitively but also in the wider variety of classroom tasks in which they may engage. In order to gauge the amount of time students spent working on various software packages, (one indicator of motivation and interest) we installed logging software which kept a record of which programs were used. We found that on average, each student used Clarisworks, a popular integrated software package which includes work processing, database, spreadsheet, graphing, and presentation modules, 25 minutes every day. Students did not necessarily have 25 minutes in class every day to use the computer-we hypothesize that the technology was a motivating factor for the students to spend more time inside and outside of class learning and doing science.

\section{Setting}

The subjects of this study were two groups of students attending the same alternative public high school in a mid-sized midwestern city. All students were in grades nine, ten, or eleven, and all were en- 
rolled in one of two science classes: Foundations of Science I or Biology. Students chose to enroll in one or the other course based on interest and scheduling constraints. Only one (pilot) section of Foundations I was offered during the 1993-1994 school year; three sections of Biology were offered. Both courses were taught by the same teacher, although the Foundations course teaching load was shared by three teachers.

Foundations $I$ is a non-traditional, interdisciplinary, project-based science class. There are three goals for the class: "to integrate the separate science disciplines, to do real science using projects as the driving force in the curriculum, and to create a classroom where the use of computational media is routine" (Heubel-Drake et al., 1994). Three high school science teachers developed the Foundations class with the support of a research project at the University of Michigan, funded by the National Science Foundation. The project, like the course, focused on the development of computational tools to encourage students' learning about science and modeling. Twenty two ninth-grade students engaged in several long-term projects during the year, including a series of investigations of a local stream, the creation of multimedia report on a technological innovation of interest to the students, and the development of computer-based museum exhibits to illustrate local geologic features. During class, students spent time sampling and analyzing stream water, collecting and identifying macro-invertebrates, and planning and completing multimedia reports and projects. They did all of their work in small groups, and did not use a textbook, except as a reference source. Student progress was monitored by teachers through ongoing assessment of project development and completion, and class participation; students took only one written test during the entire academic year.

The Biology class resembled most traditional high school Biology courses in both structure and content. Students enrolled in the course were in the ninth, tenth, or eleventh grade. The 1989 edition of Modern Biology (Towle, 1989) was used as the textbook for the course, and students studied topics including but not limited to: ecology, cells, genetics, evolution, human biology, invertebrates, and plants. Most in-class work was in the form of lectures, laboratories, or small group (library) research projects and presentations, with approximately $20 \%$ of class time spent on laboratory exercises. Students were evaluated with tests administrated approximately 8 times per semester; tests consisted largely of multiple choice questions, with some true/false questions and some short answer essays.

\section{METHODS}

The classroom teachers administered a science attitude survey entitled "Student Ideas about Science and Science Learning" to all students in the previously described classes in September of 1993 and again in June of 1994. In September students took the survey during their regular class meeting times shortly after school began; in June they completed the survey during their final exam period, where it took the place of a traditional final exam. The instrument, recently developed by Project-Based Science researchers at the University of Michigan, was designed to provide a measure of students' attitudes towards science classes and science in general, as well as to measure students' motivation for studying science. It consists of 46 Likert-style items, and was chosen because it measures three areas of interest: "Attitudes Towards Science Classes" (ATC, 14 items), "Attitudes Toward Science" (ATS, 7 items), and "Motivation for Studying Science" (MSS, 24 items). Table I lists the actual items included on the survey instrument.

Total scores on each of the three sections were computed by reversing the scale on items $9,13,23$, $24,26-29,35-40$, and 44 , and adding the responses. See Tables II and III for descriptive statistics on each scale. The reliability coefficients for each of the three scales were as follows: ATC: $\alpha=0.8679$; ATS: $\alpha=$ 0.8791; and MSS: $\alpha=0.8886$. Correlations between the three scales ranged from 0.42 to 0.67 .

\section{RESULTS AND DISCUSSION}

On the following tables are listed the means, standard deviations and other descriptive statistics for the subscale scores for Foundations and Biology students, for both September and June.

Analysis of Variance. In the analysis of variance, class and semester are independent variables; the dependent variables are scores on the three scales. On the first scale, ATC, we found statistically reliable effects by class $(\mathrm{F}(1,122)=4.07, p<0.05)$, and by semester $(\mathrm{F}(1,122)=10.98, p<0.01)$. The null hypothesis was not rejected for either of the other two scales. The analysis also indicated significant interac- 
Table I. "Student Ideas about Science and Science Learning" Survey ${ }^{a}$

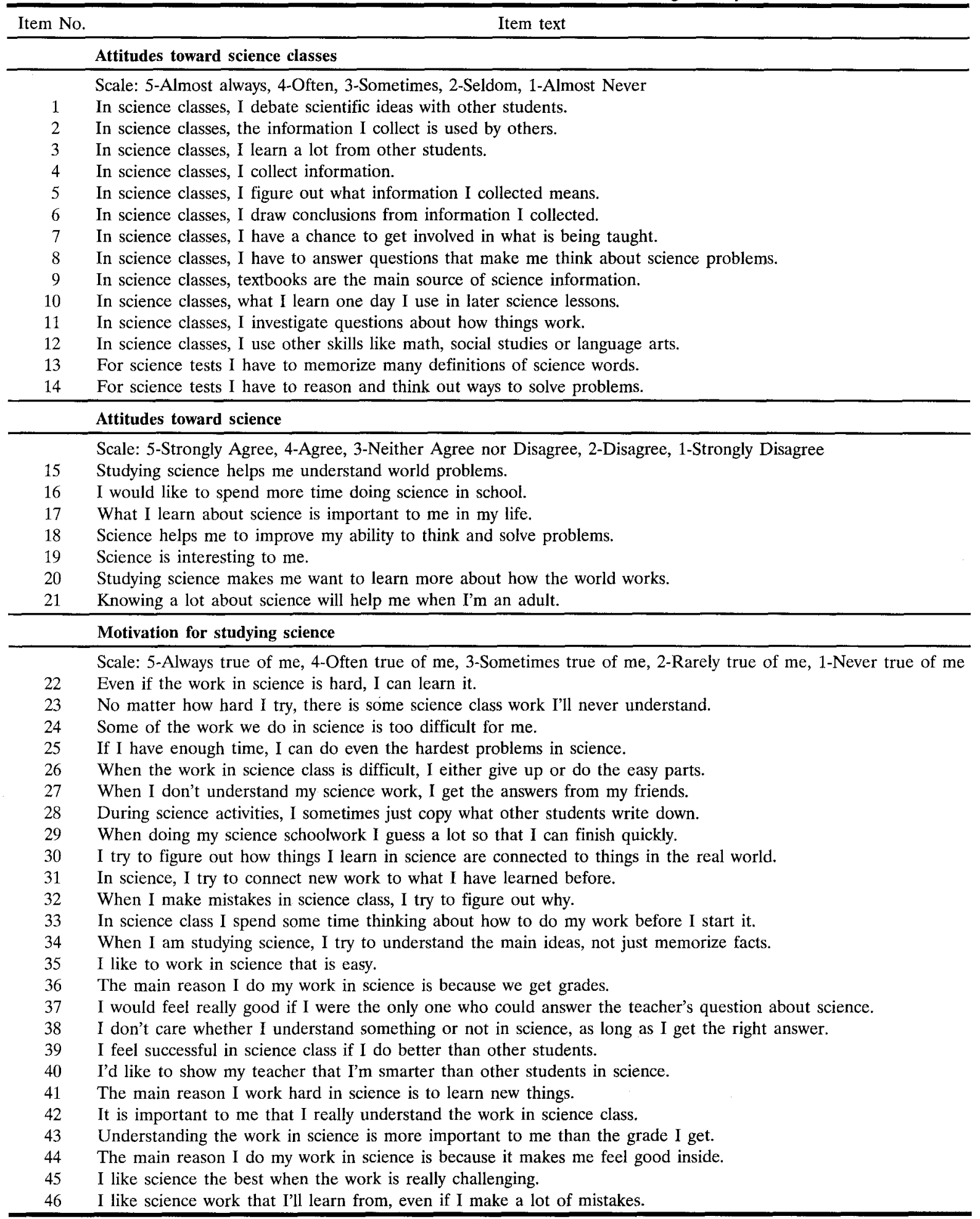

${ }^{a}$ Developed at the University of Michigan. The response scale is given at the beginning of each of the three sections. 
Table II. Survey Scores of Foundations I Students $(\mathrm{n}=21)^{a}$

\begin{tabular}{lrrrrrr}
\hline & $\mathrm{m}$ & $\mathrm{SD}$ & $\mathrm{SE}$ & Variance & Max. score & Min. score \\
\hline September & & & & & & \\
ATC & 42.71 & 5.58 & 1.35 & 31.10 & 29 & 50 \\
ATS & 23.06 & 4.04 & .98 & 16.31 & 17 & 34 \\
MSS & 84.00 & 12.26 & 2.97 & 150.38 & 64 & 107 \\
June & & & & & & \\
ATC & 56.82 & 5.23 & 1.27 & 27.40 & 47 & 68 \\
ATS & 26.00 & 2.67 & .65 & 7.13 & 22 & 31 \\
MSS & 90.71 & 9.00 & 2.18 & 80.97 & 70 & 111 \\
& & & & & & \\
\hline a & & & & & & \\
\end{tabular}

tion $(p<0.001)$ on the ATC scale between class and semester variables. Figure 1 is an interaction diagram showing the change in scores on the ATC scale for both classes, from September to June.

An effect size of 1.30 standard deviations was calculated by subtracting the June ATC means from each other and dividing by the standard deviation of the Biology group. While the two groups started out in September with similar means on the ATC scale (and Foundations a little bit lower), the Foundations group ended up in June well over one standard deviation above the Biology group.

Analysis of Scores on Individual Survey Items. We also analyzed survey items individually, comparing item means between groups and within groups. Detailed tables containing the results of the means and standard deviations for each item, and the $t$-test results for each comparison, are available from the authors, and a discussion of those findings follows.

In the fall, the two groups responded similarly on 38 of 46 items ( $83 \%$ of the items), indicating a high degree of homogeneity between the two groups. By the end of the year, however, the two groups responded similarly on only 26 of the 46 items (56\%). These differences were not equally divided among the three sections of the survey. The two groups ended significantly different on 12 of $14(86 \%)$ items in the ATC section; on 1 of $7(14 \%)$ in the ATS section; and on 7 of $19(37 \%)$ in the MSS section. Clearly the most change occurred in the ATC section of the survey, as was confirmed by the ANOVA results reported earlier.

On two of the items, $t$-tests showed both groups' June responses to be significantly different from their September responses (item 2, $p<0.001$ for both; item $26, p<0.05$ for both). Figure 2 shows a change diagram in which the fall responses are indicated by the tail of the arrow, and the spring responses by the head. In the case of item 2, both groups tend to agree more with the statement that information they collect will be used by others; however, the change in the Foundations' responses far exceeds the change in Biology students' responses. As for item 26, which deals with giving up or doing the easy part when work is difficult, the group means shifted similar amounts but in opposite directions, with Foundations students tending to agree less and Biology students tending to agree more. The similarities in item 2 might be attributed to the fact that the same teacher taught both classes, and some teaching techniques may have been in common between the two classes, causing similar changes. The differences in item 26 , however, are not intuitively related to either traditional or project-based pedagogy.

Table III. Survey Scores of Biology Students $(\mathrm{n}=64)^{a}$

\begin{tabular}{lrrrrrr}
\hline & $\mathrm{m}$ & $\mathrm{SD}$ & $\mathrm{SE}$ & Variance & Max. score & Min. score \\
\hline September & & & & & & \\
ATC & 46.20 & 9.09 & 1.34 & 82.56 & 19 & 64 \\
ATS & 23.76 & 6.21 & .90 & 37.47 & 7 & 35 \\
MSS & 84.70 & 14.65 & 2.16 & 214.62 & 49 & 115 \\
June & & & & & & \\
ATC & 47.15 & 7.39 & 1.09 & 54.67 & 23 & 61 \\
ATS & 24.78 & 5.17 & .76 & 26.75 & 7 & 35 \\
MSS & 81.83 & 11.75 & 1.73 & 138.15 & 55 & 108 \\
\hline
\end{tabular}

${ }^{a}$ Descriptive statistics for Biology students' scores on each of the three survey scales. 


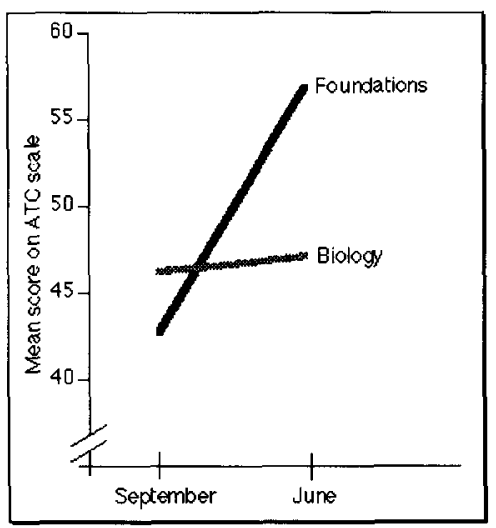

Fig. 1. Interaction diagram of Foundations I and Biology scores on the ATC scale.

In the spring, the two groups' responses on the ATC differed significantly from each other on all items except 11 and $14(p<0.05)$; in contrast, their responses were much more similar back in the fall, where statistical differences showed up on only 5 items $(1,4,7,9$, and $13, p<0.05)$. On 4 of these items in particular $(4,7,9$, and 13$)$, in which we saw differences in both fall and spring, comparison of means is revealing (see Fig. 3). In each case, the Foundations mean flip-flopped from below the Biology mean to above (or vice versa) while there was little change in the Biology mean. These items had to do with collecting information in science class, and getting involved in what's taught (Foundations stu- dents tended to agree with that statement more after the class than before), and with textbooks being the main source of information and memorizing data for tests (Foundations tended to agree much less than before). Since these questions involve project-based science distinctives (data collection, student-driven curriculum, alternative assessment, textbooks have peripheral not central role), these results make sense.

Concerning item 13 (testing), it must be pointed out that students in the Foundations I class took only one traditional written assessment during the year, and this test contained a number of short essay questions, in addition to multiple choice and true/false questions which might require memorizing definitions. Instead, students were assessed on the basis of their work on written or multimedia-based reports and projects. As a result, students' ideas about the nature of science tests could be expected to change significantly, as demonstrated by their responses to the item about science tests. On the other the hand, in Biology, students regularly took multiple choice, true/false, and fill-in-theblank exams, and hence would have less reason to change their impressions about science tests. This might explain the large change in their overall responses to this item on the survey.

As indicated before, the two groups responded differently to only 8 items in the fall (no difference between means on 38 of 46 items), on the whole instrument. Of those 38 items for which there was no difference in the fall, 14 of them showed differences in the spring, and of those 14, Foundations spring

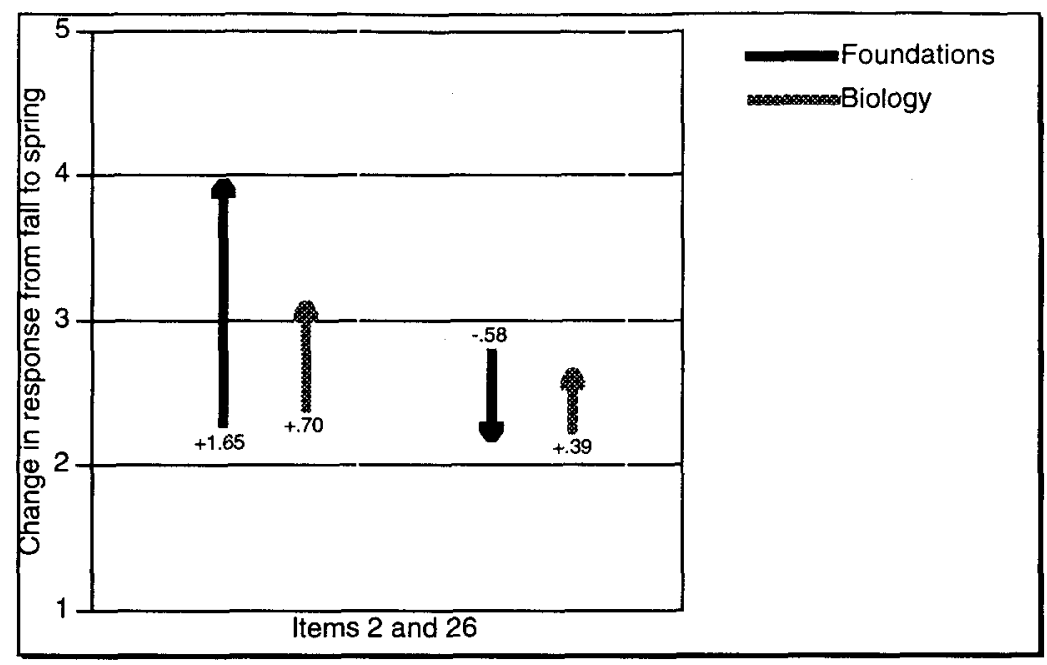

Fig. 2. Change diagram showing change in means of items for which September means differed significantly from June means in both groups. 


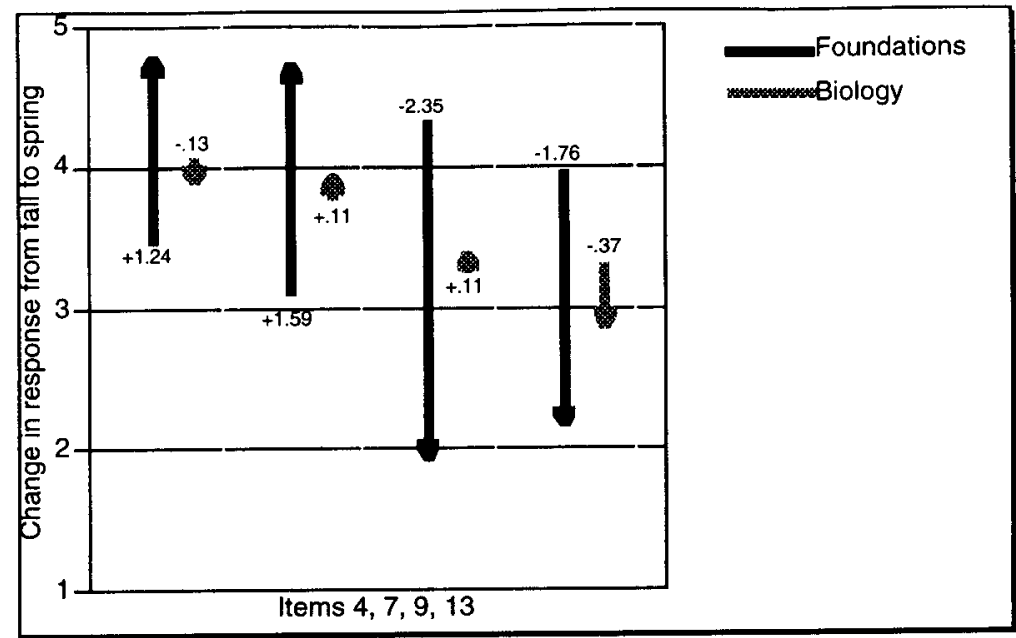

Fig. 3. Change diagram showing change in means of items for which both groups differed significantly from each other both in June and September.

means changed significantly from fall means on 6 of them (items 2, 3, 5, 6, 8 and 18, $p<0.01$ for all except for item $5, p<0.05$ ) while Biology showed no significant change. Again, a closer inspection of the patterns of change is revealing (see Fig. 4). For each of these items, the Foundations attitudes changed for the better while the Biology attitudes remained virtually the same (except for item $2, p<0.01$ ). These items dealt with information (information I collect is used by others, I figure out what information I collect means, I draw conclusions about information), solving problems (I answer questions that make me think about science problems, science helps me think and solve problems), and peer collaboration (I learn a lot from other students). This result is particularly significant when one considers the goals of the Foundations I class. The teachers who developed the course consistently place an emphasis on providing opportunities for students to identify and solve authentic science-related problems by collecting, analyzing and

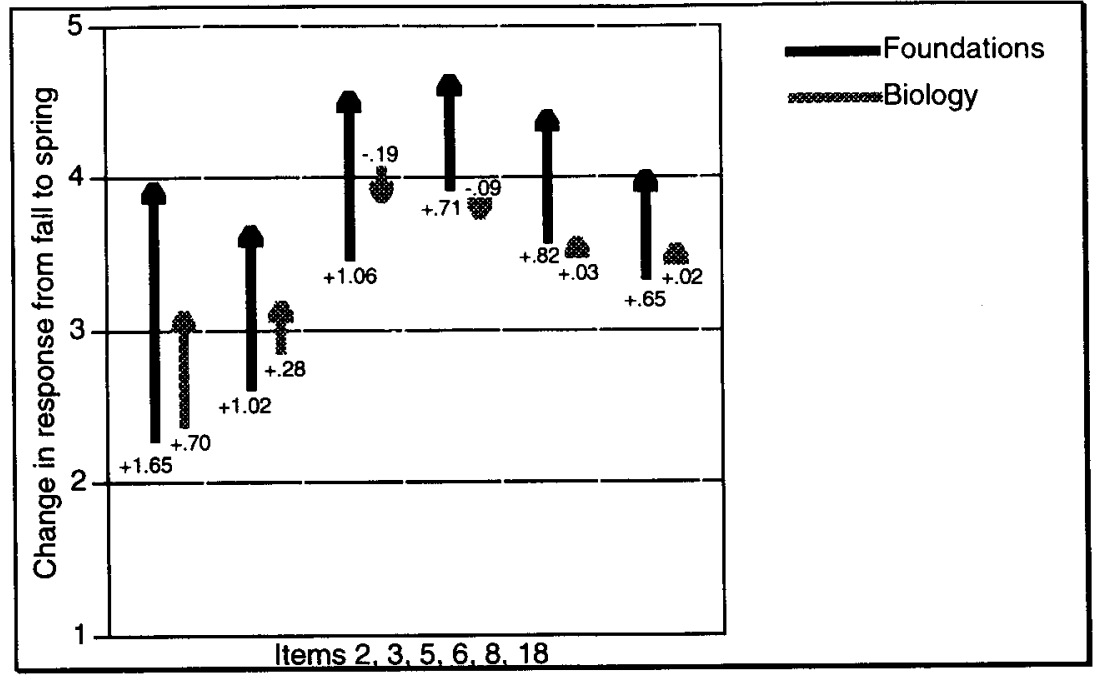

Fig. 4. Change diagram showing change in means of items for which both groups were the same in the fall, different in the spring, and Foundations showed significant differences. 


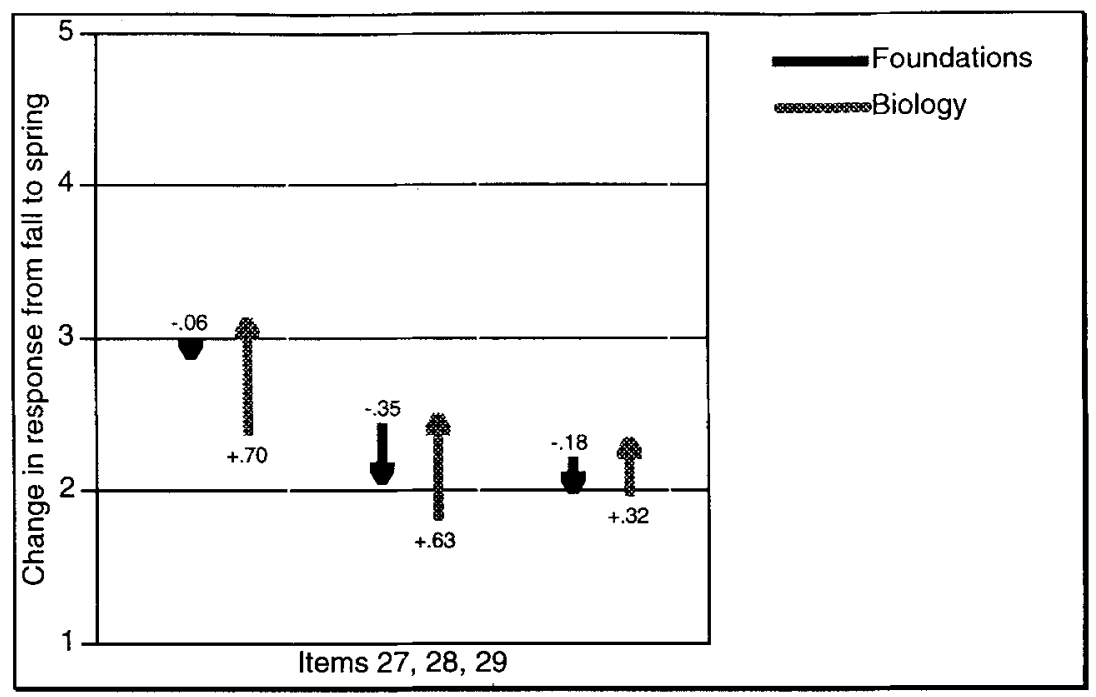

Fig. 5. Change diagram showing change in means of items for which Biology showed significant differences.

synthesizing real data, and this consistent emphasis seems, at least from the point of view of students' attitudes, to be having a positive effect.

These items are also particularly interesting when one considers certain other differences between the two classes. First, in Foundations I, students did most (if not all) of their work in collaborative groups; in Biology, most work was individual. Second, in Foundations I students regularly shared their work, either by exchanging and combining data for analysis by the class as a whole, or by making presentations of results to the rest of the class. In Biology, although students did make some class presentations, their presentations were not on topics studied by all students, and they did not exchange data. From Foundations I students' responses to this part of the survey, it is clear that those goals were realized.

On three other items $(27,28$, and 29$)$, statistically significant differences appeared for the Biology scores from fall to spring $(p<0.05)$. Figure 5 shows a change diagram for those three items. For item 27, Foundations started off different from Biology, ended up similar; for item 28 , they started off different and ended up different; for item 29, they started off similar and ended up different (all $p<$ 0.05 ). Interestingly enough, these items all deal with classroom work habits (I get answers from my friends, sometimes I copy from my friends, I guess a lot to finish quickly). The change diagram shows that the Biology students tended to agree much more with these statements as the year progressed, while Foundations students tended to agree less, although not significantly. Perhaps in the traditional, contentdelivery classroom, if students can't keep up they tend to resort to counter-productive work strategies in order to finish their work.

\section{CONCLUSIONS}

In general, the results of this study suggest that providing students with opportunities to collect and analyze their own data in science classes results in a marked change in students' ideas about science classrooms. Foundations I students' increased tendency to agree with statements about 'using information,' 'drawing conclusions,' and 'thinking about problems,' implies a change in their understanding of what it means to do science in school. These students, in contrast to students in the traditional Biology course, no longer describe their science classroom experience as one of memorization, textbook reading, and test taking. Instead they see science class as a place in which they can work with others to collect data, draw conclusions, and formulate and solve problems. No significant indications of change in attitudes toward science or in motivation for studying were noted. Perhaps the one-school-year time frame of involvement with project-based science may have been insufficient to positively affect motivation or attitudes toward science in general. If we are interested in changing students' ideas about science classes, then classrooms of the sort described here seem to show promise. 


\section{ACKNOWLEDGMENT}

This research has been supported by the National Science Foundation (RED 9353481) and the University of Michigan.

\section{REFERENCES}

Blumenfeld, P., Krajcik, J., Marx, R., and Soloway, E. (1994). Lessons Learned: How Collaboration Helped Middle School Teachers Learn Project Based Instruction. The Elementary School Journal 94(5): 539-551.
Heubel-Drake, M., Mouradian, M., and Stern, E. (1994). Foundations I Syllabus, Fall 1994. Unpublished class handout.

Hounshell, P., and Hill, S. (1989). The Microcomputer and Achievement and Attitudes in High School Biology. Journal of Research in Science Teaching, 26(6): 543-549.

Krajcik, J., Blumenfeld, P., Marx, R., and Soloway, E. (1994). A Collaborative Model for Helping Science Teachers Learn Projectbased Instruction. The Elementary School Joumal, 94(5): 483-498.

Marx, R., Blumenfeld, P., Krajcik, J., Blunk, M., Crawford, B. Kelly, B., and Meyer, K. (1994). Enacting Project-based Science: Experiences of Four Middle Grade Teachers. The Elementary School Journal, 94(5): 517-538.

Roupp, R. R., Gal, S., Drayton, B., and Pfister, M. (Eds.), (1992). LabNet: Toward a Community of Practice. Erlbaum, Hillsdale, New Jersey.

Towle, A. (1989). Modern Biology, Holt, Rinehart and Winston, New York. 